\title{
Relation between high density lipoprotein particles concentration and cardiovascular events: a meta-analysis
}

\author{
YuJing Wu, ZhiJuan Fan, YaQiong Tian, Shuang Liu and ShuYe Liu*
}

\begin{abstract}
Background: Trails aimed at raising high density lipoprotein(HDL) cholesterol concentration failed to make better cardiovascular outcomes. HDL particles may be better biomarkers reflecting properties of HDL. This meta-analysis was conducted to evaluate the relation between blood HDL particles level and cardiovascular events.

Methods: PubMed and other databases were searched for eligible studies and NewCastle-Ottawa Quality Assessment Scale(NOS) was used to assess the quality of included studies. A random or fixed-effect model was applied to calculate the pooled hazard ratio(HR).

Results: Twelve studies were finally included. The pooled HR(95\%confidence interval) for per standard deviation(SD) increment and top quartile versus bottom quartile were $0.79(0.72,0.86)$ and $0.65(0.57,0.75)$, respectively. Subgroup analysis suggested that HR was significantly lower in subjects with a cardiovascular disease(CVD) history than that of people without established CVD. Subclass analysis indicated that HRs for per SD increment of small(0.85) and medium(0.84) HDL particles were significantly lower than that of large HDL particles(0.96).
\end{abstract}

Conclusions: $\mathrm{HDL}$ particle level in blood was inversely related to CVD events, indicating that $\mathrm{HDL}$ particles maybe a protective factor in patients with CVD, thus making HDL particles a potential biomarker and therapy target.

Keywords: HDL, Particle, Cardiovascular events, Meta analysis

\section{Background}

It is well acknowledged that high density lipoproteins (HDL) play a role in anti-atherosclerosis and protect against the development of cardiovascular diseases (CVD). Serum concentrations of HDL cholesterol (HDL-C), the most widely used biomarker about HDL, are inversely related to risk of atherosclerotic CVD. But trails aimed at increasing HDL-C failed to improve CVD outcomes [1, 2], raising the question whether HDL-C is the best biomarker for assessing the relationship between HDL and CVD risk.

Indeed, HDL is a kind of heterogeneous population of lipoproteins, representing a spectrum of lipoprotein particles ranging $1.063-1.21 \mathrm{~g} / \mathrm{ml}$ in density and 7-12 $\mathrm{nm}$ in size. Since HDL-C may not fully represent the properties of HDL, alternative biomarkers and parameters of HDL,

\footnotetext{
* Correspondence: liushuye@tijmu.edu.cn

Third Central Hospital of Tianjin, Tianjin Institute of Hepatobiliary Disease, Tianjin Key Laboratory of Artificial Cell, Artificial Cell Engineering Technology Research Center of Public Health Ministry, No. 83, Jintang Road, Hedong District, Tianjin, China
}

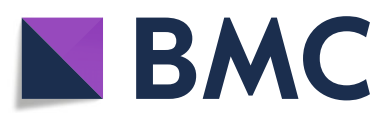

(c) The Author(s). 2018 Open Access This article is distributed under the terms of the Creative Commons Attribution 4.0 International License (http://creativecommons.org/licenses/by/4.0/), which permits unrestricted use, distribution, and reproduction in any medium, provided you give appropriate credit to the original author(s) and the source, provide a link to the Creative Commons license, and indicate if changes were made. The Creative Commons Public Domain Dedication waiver (http://creativecommons.org/publicdomain/zero/1.0/) applies to the data made available in this article, unless otherwise stated. such as the concentration of HDL particles (HDL-P), HDL size and apolipoprotein A1 (apoA1), are getting more attentions. Several studies evaluated the association between HDL-P and CVD outcomes, indicating that HDL-P may be a parameter making more sense in predicting CVD outcomes than HDL-C. In this study, we performed a meta-analysis to explore the relationship between HDL-P and CVD outcomes.

\section{Methods}

Selection criteria

Clinical studies were considered eligible if they satisfied the following inclusion criteria: 1) the studies about the association between concentration of HDL-P in plasma or serum and CVD outcomes; 2) Hazard ratio(HR) or odds ratio(OR) adjusted for potential influencing factors with 95\% confidence interval(CI) should be available; 3 ) more than 50 patients should be involved in the study. Studies were excluded on any of the following criteria: 


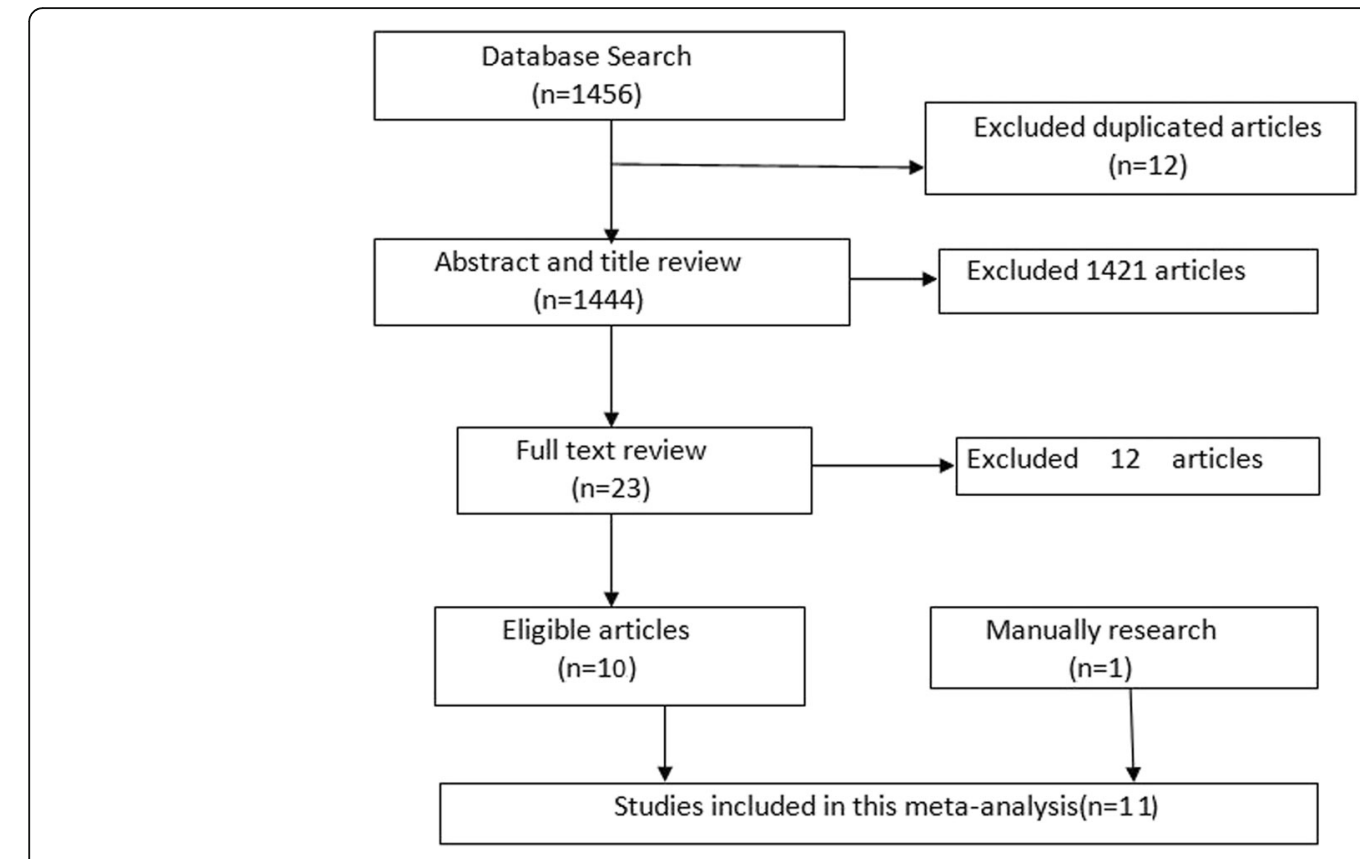

Fig. 1 Flowchart of the included studies

1) review articles or case reports; 2) If studies were published by the same group with overlapping patient populations, the most recent one was selected.

\section{Search strategy}

We searched the PubMed, Cochrane Library, China National Knowledge Infrastructure(CNKI) and Weipu (VIP) database using varying combinations of the following keywords: "high density lipoprotein", "HDL" "subclasses", "particles", "subpopulation", "subfraction"; "CVD", "cardiovascular diseases", "cardiovascular events", "cardiac events". The results were limited to English and Chinese language. The last search update was performed on November 20,2016. References of all eligible studies were manually searched for additional eligible studies.

Table 1 Characteristics of the Eligible studies

\begin{tabular}{|c|c|c|c|c|c|c|}
\hline First Author & $\begin{array}{l}\text { Year of } \\
\text { publication }\end{array}$ & Study design & $\begin{array}{l}\text { Sample size(case+control/ } \\
\text { events+free of events) }\end{array}$ & Area & Age(years) & Quality score \\
\hline Mackey & 2012 & cohort study & $5597(227+5370)$ & US & mean of 61.5 & 9 \\
\hline \multirow[t]{2}{*}{ Hsia } & \multirow[t]{2}{*}{2008} & \multirow{2}{*}{$\begin{array}{l}\text { nested case- } \\
\text { control study }\end{array}$} & group1:404(202 + 202) & \multirow[t]{2}{*}{ US } & \multirow[t]{2}{*}{50 to 79} & \multirow[t]{2}{*}{7} \\
\hline & & & group2:304(152+152) & & & \\
\hline Akinkuolie & 2014 & cohort study & $\begin{array}{l}\text { model 1: 25706 }(947+24,759) \\
\text { model 2: } 25232(911+24,321)\end{array}$ & US & $\begin{array}{l}\text { Free of events: median } \\
\text { of } 52.6 \text {; Events:median } \\
\text { of } 57.9\end{array}$ & 9 \\
\hline Berger & 2012 & $\begin{array}{l}\text { nested case- } \\
\text { control study }\end{array}$ & $1372(686+686)$ & US & median of 69 & 8 \\
\hline Duprez & 2009 & $\begin{array}{l}\text { nested case- } \\
\text { control study }\end{array}$ & $728(248+480)$ & cross-country & median of 49 & 5 \\
\hline Kuller & 2007 & case control study & $428(214+214)$ & US & mean of 51.3 & 8 \\
\hline Otvos & 2006 & $\begin{array}{l}\text { nested case- } \\
\text { control study }\end{array}$ & $1061(364+697)$ & US & mean of 64.4 & 7 \\
\hline Chandra & 2015 & cohort study & 1977 & US & not given & 8 \\
\hline Parish & 2012 & cohort study & $20,021(1796+18,225)$ & UK & 40 to 80 & 8 \\
\hline Musunuru & 2009 & cohort study & $4594(337+4257)$ & Sweden & not given & 9 \\
\hline Harchaoui & 2009 & $\begin{array}{l}\text { nested case- } \\
\text { control study }\end{array}$ & $2223(822+1401)$ & UK & mean of 65 & 9 \\
\hline
\end{tabular}




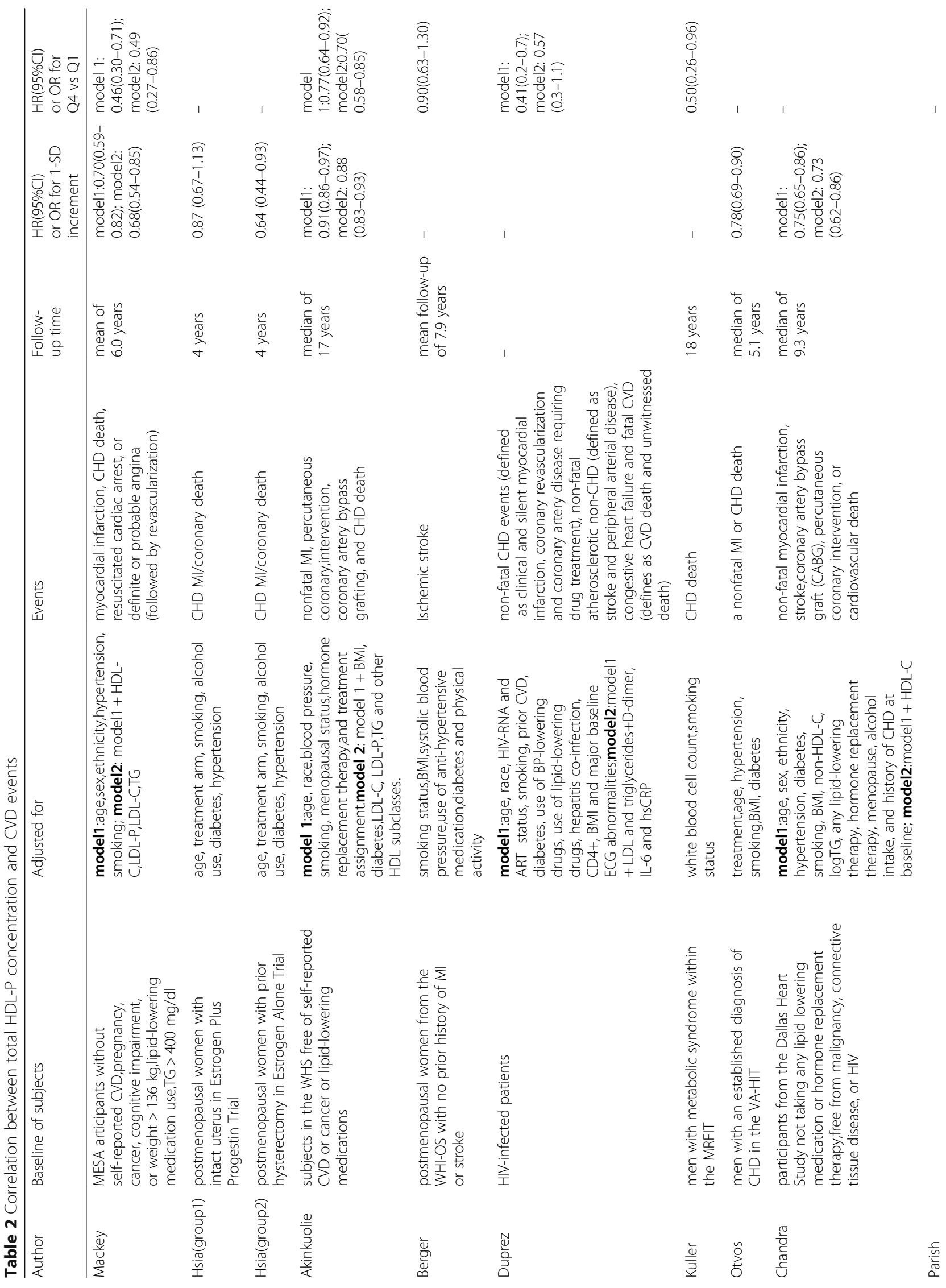




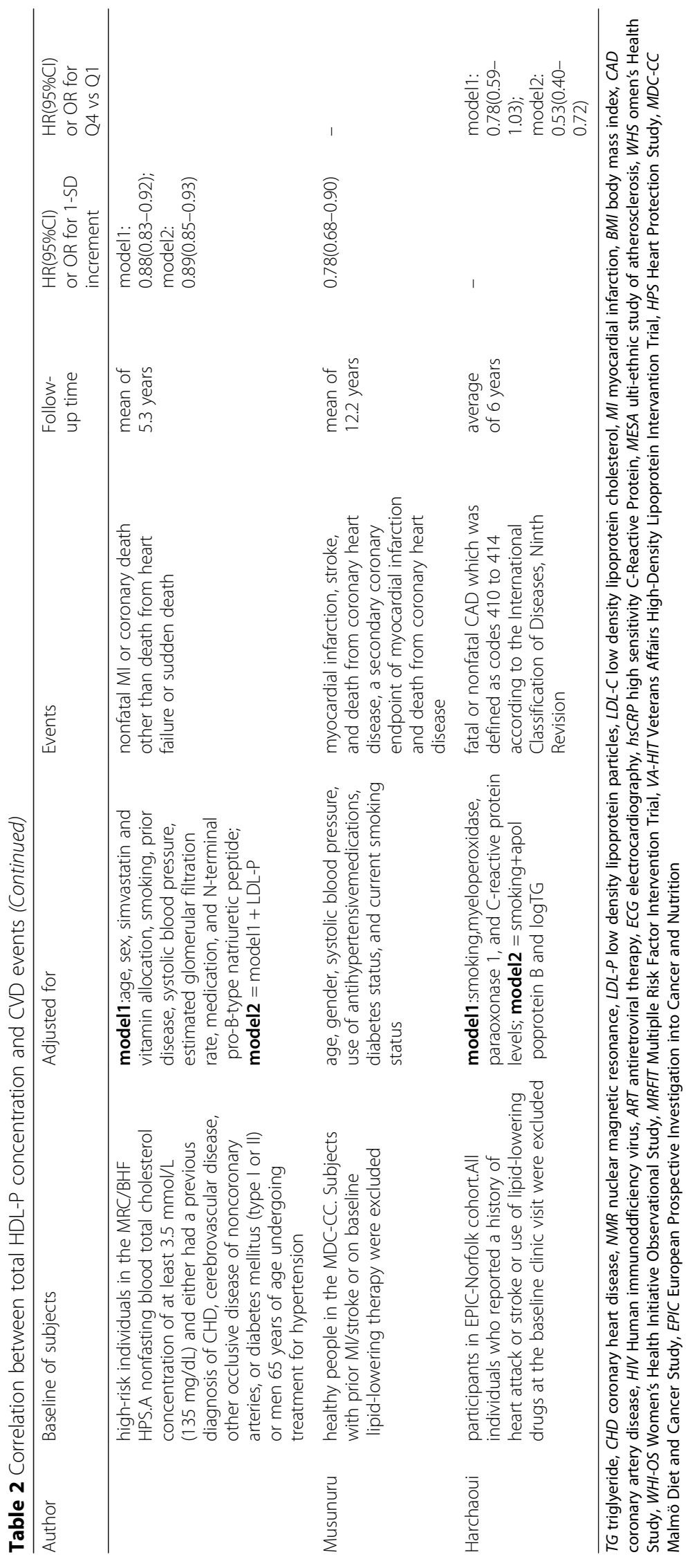




\section{Quality assessment and data extraction}

The quality of articles was assessed using NewCastleOttawa Quality Assessment Scale (NOS) [3, 4], by two investigators independently. Disagreement was resolved by discussion and consulting a third investigator.

Two investigators collected following information from all the included articles independently: first author's name, publication year, study design, sample size, basic status of subjects(country, age, disease status, treatment), detection method for HDL-P, definition of outcome events, follow-up time, HR/OR for total HDL-P and HDL-P subclasses if applicable.

\section{Statistical methods}

STATA 11.0 software was used to perform all statistical analyses. Forest plots were used to assess the pooled HR of HDL-P concentration for CVD events. The $I^{2}$ test was performed to estimate the heterogeneity between articles. $I^{2}$ more than $50 \%$ indicated significant heterogeneity and a

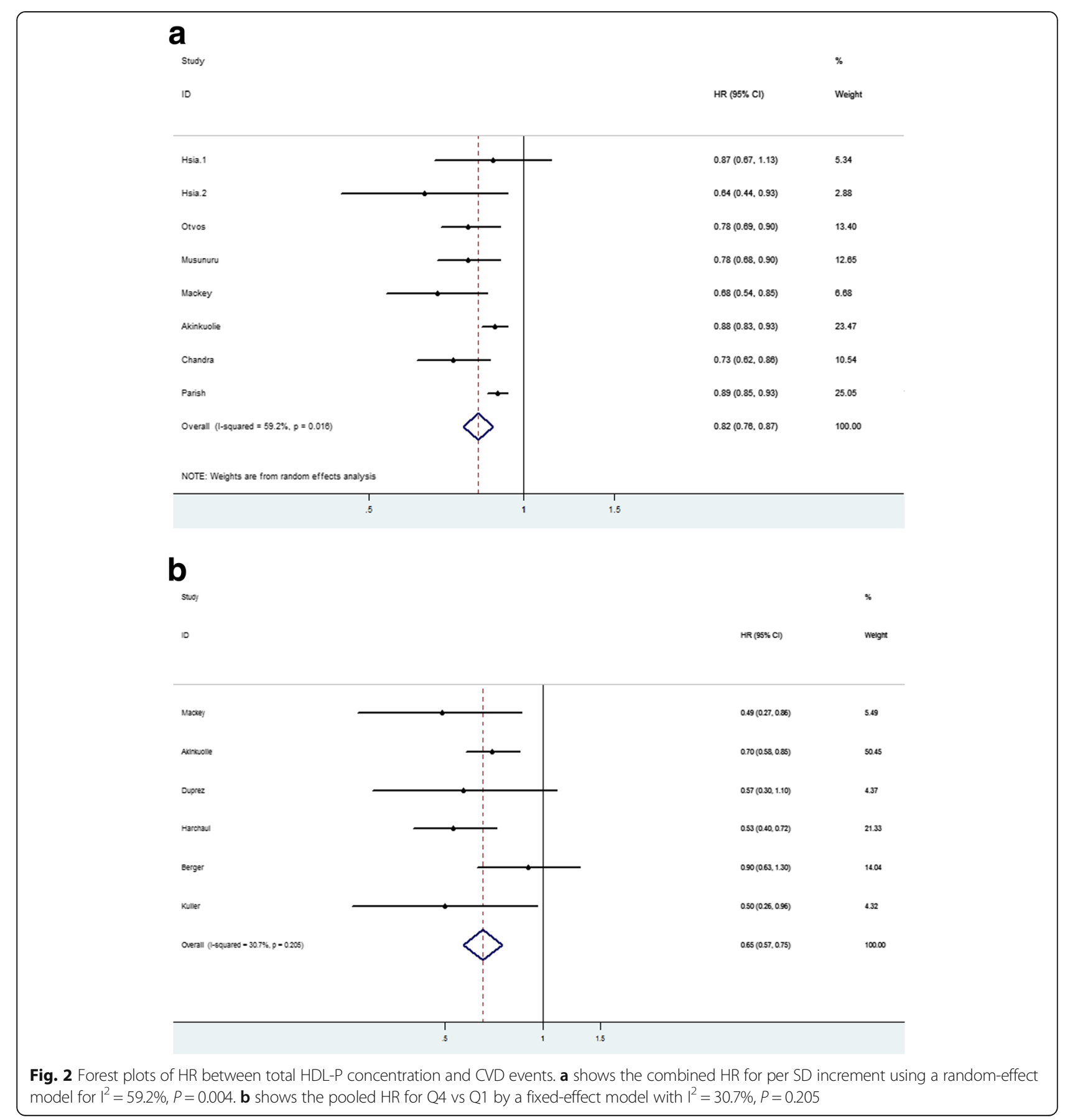


random-effect model was applied. Otherwise, a fixedeffect model was used. Subgroup analysis was conducted to determine the source of heterogeneity. Heterogeneity was also investigated by sensitivity analysis, which was performed by removing each study sequentially to assess the impact of each study. Potential publication bias was assessed with funnel plots and the Begg's test. $P$ value $<0.05$ was considered as statistically significance.

\section{Results}

\section{Eligible studies and quality assessment}

Flowchart of study selection was illustrated in Fig. 1. Eleven studies [5-15] were finally included in this metaanalysis. The basic characteristics and quality assessment result of the eligible articles were shown in Table 1.

Since two groups in Hsia's study [12] used different subjects without overlapping, we treated this study as two independent ones in following analysis. Two models were established in Akinkuolie's [5] study because of different influencing factors adjusted for. There existed overlapping subjects. The whole sample size was 26,332(data not shown). Eleven articles with 63,064 subjects were involved in this meta-analysis. Seven out of the 11 studies were conducted in America.

We used NOS to evaluate the quality of eligible articles. The full score is nine in NOS system. Duprez's study [9] scored as five, ranking normal in quality assessment. Others got scores higher than 6 , ranking as high quality. And there were four studies getting full marks in NOS quality assessment.

\section{Correlation between total HDL-P concentration and CVD events}

As shown in Table 2, HR or OR was calculated for per standard deviation(SD) increment or top quartile (Q4) versus bottom quartile (Q1) and we calculated pooled $\mathrm{HR}(\mathrm{OR})$ for both per SD increment and Q4 vs Q1. The combined HR for per SD increment was $0.82(95 \%$ CI:0.76,0.87) using a random-effect model for $\mathrm{I}^{2}=59.2 \%, P=0.004$ (Fig. 2a). The pooled HR for Q4 vs Q1 was $0.65(95 \% \mathrm{CI}$ : 0.57,0.75) calculated by a fixed-effect model with $\mathrm{I}^{2}=30.7 \%$,
$P=0.205$ (Fig. 2b). Both indicated that a higher HDL-P level was reversely related with CVD events. The forest plots were drawn in Fig. 2.

\section{Assessment of heterogeneity}

Evidence of heterogeneity existed in HR for per SD increment. No heterogeneity was detected in HR for Q4 vs Q1. So subgroup meta-analysis was conducted to explore the source of heterogeneity in studies about HR for per SD increment. We divided studies into different subgroups according to study design, baseline status(patients with a history of CVD or not), influencing factors adjusted for (adjusting for lipids or not). There were two models in each of Mackey's [7], Akinkuolie's [5], Chandra's [6] and Parish's [13] studies. Compared to model 1, model 2 was additionally adjusted for lipids. Table 3 shows the metaanalysis results of subgroups. No grouping basis could explain heterogeneity fully, but case-control studies and studies only about females got $\mathrm{I}^{2}<50 \%$ and $P>0.1$, indicating insignificant heterogeneity.

Also, sensitivity analysis was conducted by omitting the studies one by one and repeating the meta-analysis. But heterogeneity remained significant with single study removal. Heterogeneity became insignificant with the removal of Akinkuolie's [5] study together with Parish's [13] $\left(\mathrm{I}^{2}=0.0 \%, P=0.658\right)$. The pooled HR was $0.76(95 \%$ CI: $0.71,0.82$ ) with no significant difference from the HR with these two articles included.

\section{Meta-analysis about HDL-P subclasses}

We also collected the data about HR or OR for HDL-P subclasses and CVD events. The diameter ranges of large, medium and small HDL-P were $8.8-14.0 \mathrm{~nm}$, $8.2-8.8 \mathrm{~nm}, 7.3-8.2 \mathrm{~nm}$, respectively. Seven articles analyzed the relation between levels of large HDL-P and CVD events. Four studied the relation between levels of medium HDL-P and CVD events. Five studied the relation between levels of small HDL-P with CVD events. HRs was calculated for per SD increment and Q4 versus Q1. Forest plots were shown in Fig. 3. In Fig. 3a, HRs were calculated for per SD increment. Subtotal HRs of large, medium and

Table 3 Meta-analysis results of subgroups

\begin{tabular}{llllll}
\hline Subgroups & & $I^{2}(\%)$ & $P$ & Pooled $\mathrm{HR}$ & $95 \% \mathrm{Cl}$ \\
\hline study design & case-control & 0.0 & 0.418 & 0.78 & $0.70,0.88$ \\
& cohort & 69.0 & 0.001 & 0.83 & $0.79,0.88$ \\
sex & female only & 18.6 & 0.297 & 0.89 & 0.80 \\
& both & 73.3 & 0.001 & $0.74,0.86$ \\
baseline status & no CVD history & 74.7 & 0.003 & 0.82 & $0.74,0.89$ \\
& partly with CVD & 60.0 & 0.029 & 0.84 & $0.78,0.89$ \\
influencing factors & adjusted for lipids & 70.1 & 0.018 & $0.77,0.91$ \\
adjusted for & not adjusted for lipids & 65.2 & 0.005 & 0.81 & $0.76,0.87$ \\
\hline
\end{tabular}


a

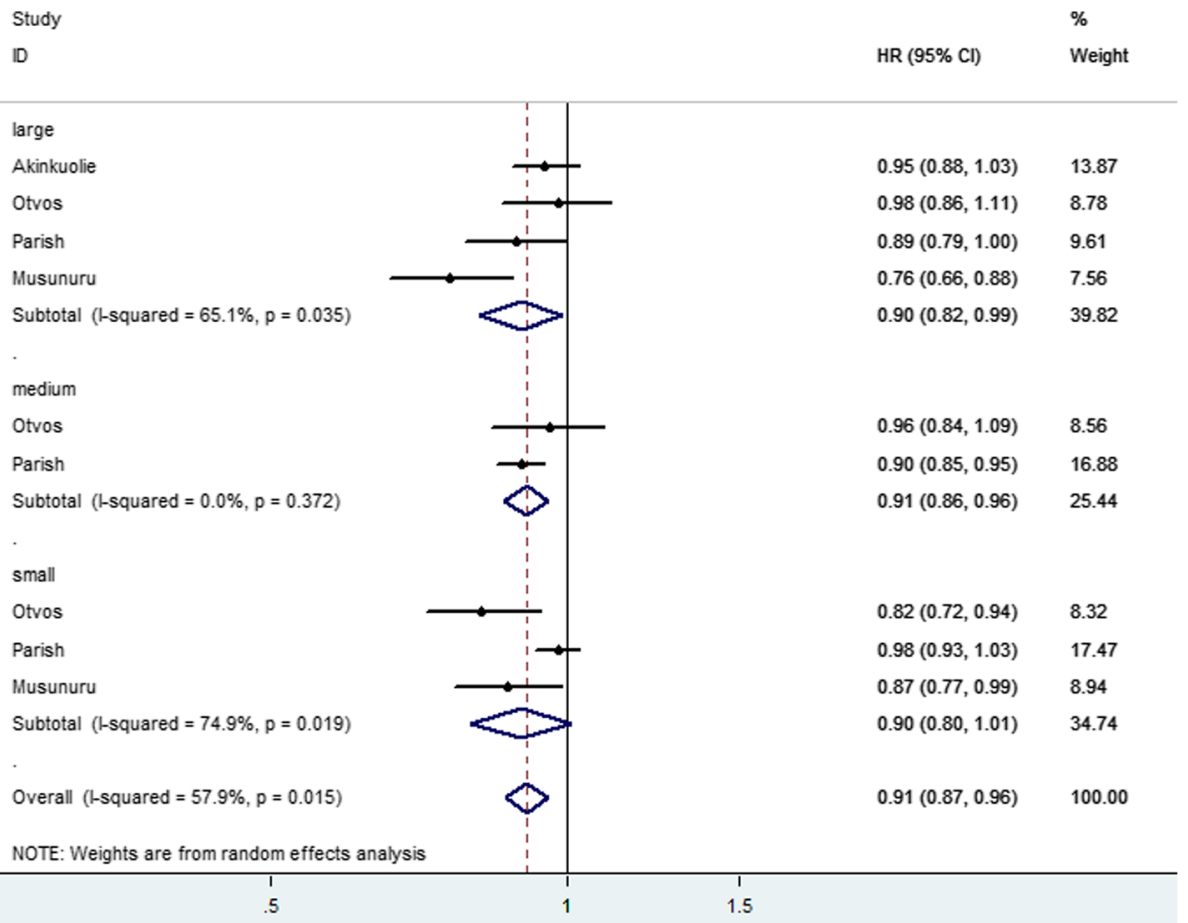

b

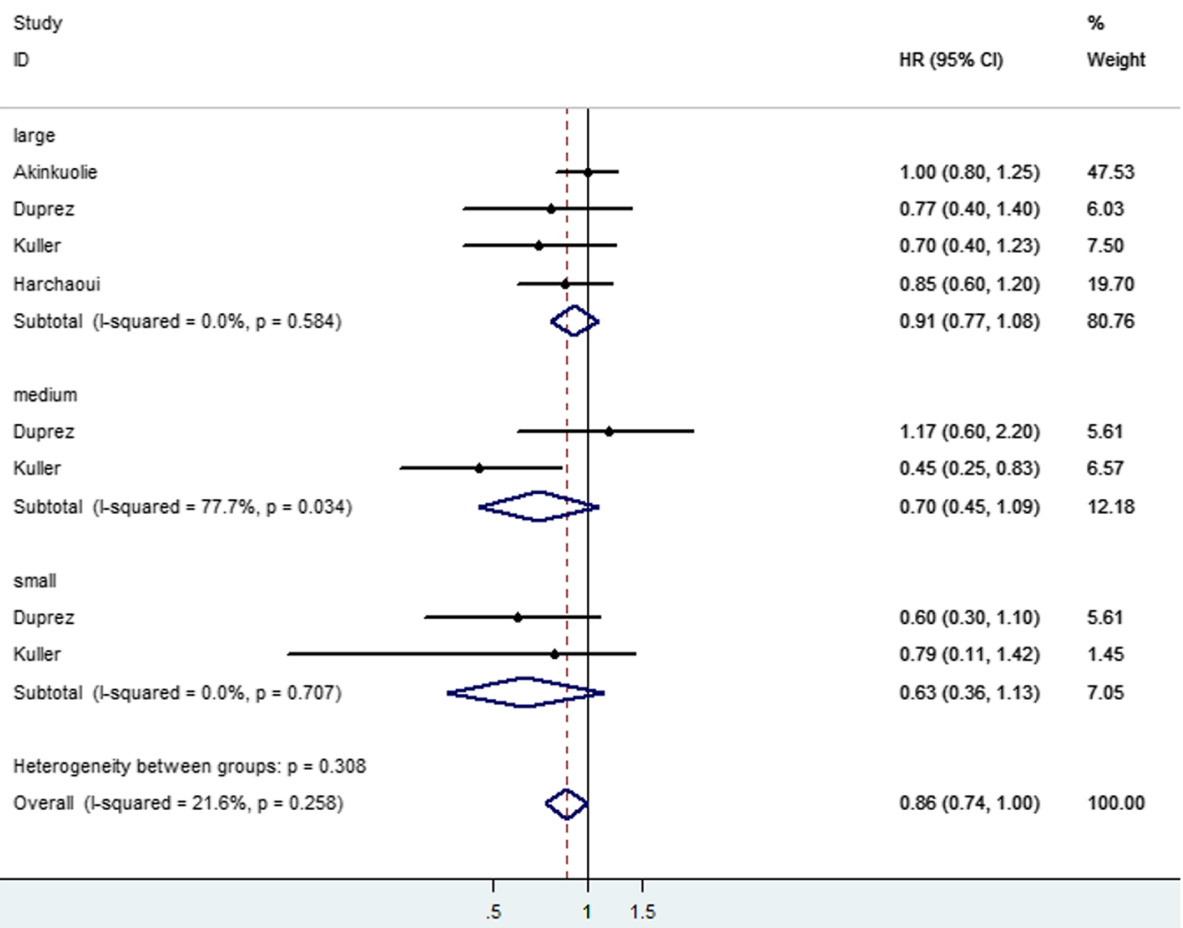

Fig. 3 Forest plots for small, medium and large HDL-P. a HRs were calculated for per SD increment. b HRs were calculated for Q4 vs Q1

small HDL-P were 0.90(0.82,0.99), 0.91(0.86,0.96) and $0.90(0.80,1.01)$, respectively. In Fig. 3b, no significant difference was observed in HRs of HDL-P subclasses.

\section{Assessment of publication bias test}

As Fig. 4 shows, studies included were symmetrical. As shown in Fig. 4,the Begg's funnel plots of eight studies 

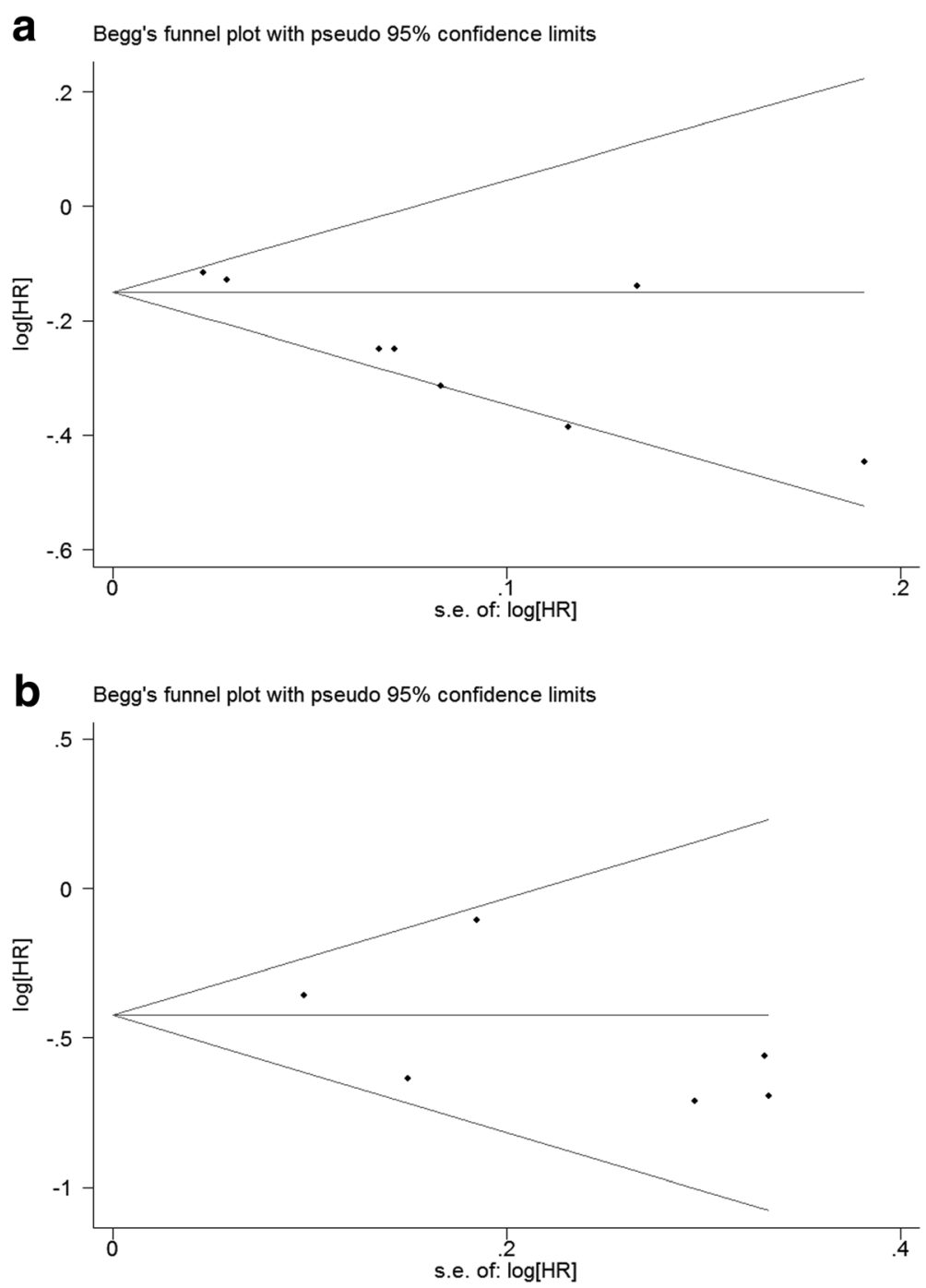

Fig. 4 funnel plots of included studies. a shows the Begg's funnel plots of studies about HR calculated for per SD increment. b shows the Begg's funnel plots of studies about HR calculated for Q4 vs Q1

about HR calculated for per SD increment(Fig. 4a) and Q4 vs Q1(Fig. 4b) were almost $\operatorname{symmetric}(P=0.108$, 1.00 , respectively),suggesting a low likelihood of publication bias.

\section{Discussion and conclusions}

It is well established that serum HDL takes a cardioprotective role and is reversely related with CVD events risk. Functions of HDL include its role in reverse cholesterol transport (RCT), anti-oxidation and anti-inflammation. In this metaanalysis, we searched and analyzed studies about the value of blood HDL-P levels in predicting incident CVD events.

Results of meta-analysis showed that the pooled HR (or OR) for per SD increment and Q4 versus Q1 of blood HDL-P level was 0.82 and 0.65 , 95\% CI ranging from 0.76 to 0.87 and 0.57 to 0.75 , respectively. Same as established theories, our data indicates that higher HDL$P$ level maight be a protective factor for CVD events.

We also analyzed clinical value of different HDL-P subfranctions in predicting CVD events. HRs for per SD increment of large, medium and small HDL-P were 0.90, 0.91 and 0.90 , with no significant difference. But the results of Kim's study [16], small and medium HDL-P were significantly and inversely correlated with carotid intima-media thickening measurement results. The possible reason was that the relation between small and medium HDL-P with cardioprotective paraoxonase 1 activity may represent the function of HDL. But HRs for Q4 versus Q1 were 0.91, 0. 70 and 0.63 , respectively. And 95\% CI of HRs for Q4vsQ1 cover 1 . One possible explanation was the shortage of studies included. Four $[5,8,9,14]$ studies explored the association between large HDL-P levels and CVD events. Only two $[8,9]$ researches studied medium and small HDL-P. 
HDL particles spectrum changes in the whole HDL metabolism. And different HDL-P subclasses have varied functions. Small HDL-P seems to have a stronger antiinflammatory effect than large HDL-P [17]. Large HDL-P is reported to have the property of inhibiting platelet activation and stimulating the activation of anti-coagulant proteins [18]. Since the structure and ingredient of HDL particle vary in the process of HDL metabolism, amounts of HDL-C and apolipoprotein A1 differ in different HDL particles. Large HDL-P contains more cholesterol inside. So HDL-C may not reflect the whole function and amount of HDL in blood. HDL-P may be a promising biomarker for CVD events and a new target of therapy.

Heterogeneity existed in pooled HR for per SD increment, but not Q4vsQ1. Sensitivity analysis demonstrated removal of Akinkuolie's [5] and Parish's [13] studies made heterogeneity insignificant. No publication bias was observed. With 63,064subjects included, total sample size was large in this meta-analysis study. Our study came to a robust result that blood HDL-P concentration is a promising biomarker reversely related to CVD events, regardless of patients' basic status.

\section{Abbreviations}

BMI: Body mass index; CHD: Coronary heart disease; Cl: Confidence interval; CVD: Cardiovascular disease; EPIC: European Prospective Investigation into Cancer and Nutrition; HDL: High density lipoprotein; HIV: Human immunoddficiency virus; HPS: Heart Protection Study; HR: Hazard ratio; hsCRP: High sensitivity C-Reactive Protein; MDC-CC: Malmö Diet and Cancer Study; MESA : Ulti-ethnic study of atherosclerosis; MI: Myocardial infarction; MRFIT: Multiplle Risk Factor Intervention Trial; NMR: Nuclear magnetic resonance; NOS: NewCastle-Ottawa Quality Assessment Scale; OR: Odds ratio; SD: Standard deviation; TG: Triglyeride; VA-HIT: Veterans Affairs High-Density Lipoprotein Intervantion Trial; WHI-OS: Women's Health Initiative Observational Study; WHS: Women's Health Study

\section{Availability of data and materials}

All data analyzed during this study are included in the references.

\section{Authors' contributions}

YJW designed this study and performed the statistical analysis. ZJF and YQT searched the databases for eligible studies. SL was a major contributor in writing the manuscript. SYL was a major contributor in acquisition of data and analysis of data. All authors read and approved the final manuscript.

\section{Ethics approval and consent to participate}

Not applicable.

\section{Competing interests}

The authors declare that they have no competing interests.

\section{Publisher's Note}

Springer Nature remains neutral with regard to jurisdictional claims in published maps and institutional affiliations.

Received: 27 November 2017 Accepted: 3 April 2018

Published online: 19 June 2018

\section{References}

1. Group HTC. HPS2-THRIVE randomized placebo-controlled trial in 25673 high-risk patients of ER niacin/laropiprant: trial design, pre-specified muscle and liver outcomes, and reasons for stopping study treatment. Eur Heart J. 2013;34(17):1279-91.
2. Schwartz GG, Olsson AG, Abt M, Ballantyne CM, Barter PJ, Brumm J, Chaitman BR, Holme IM, Kallend D, Leiter LA, et al. Effects of dalcetrapib in patients with a recent acute coronary syndrome. N Engl J Med. 2012;367(22):2089-99.

3. Wells G, Shea B, O'Connell D, Peterson J, Welch V, Losos M, Tugwell P: NewCastle-Ottawa quality assessment scale-case control studies[EB/OL]. 2011.

4. Wells G, Shea B, O'Connell D, Peterson J, Welch V, Losos M, Tugwell P. NewCastle-Ottawa quality assessment scale-cohort studies[EB/OL]. 2011.

5. Akinkuolie AO, Paynter NP, Padmanabhan L, Mora S. High-density lipoprotein particle subclass heterogeneity and incident coronary heart disease. Circ Cardiovasc Qual Outcomes. 2014;7(1):55-63.

6. Chandra A, Neeland IJ, Das SR, Khera A, Turer AT, Ayers CR, McGuire DK, Rohatgi A. Relation of black race between high density lipoprotein cholesterol content, high density lipoprotein particles and coronary events (from the Dallas heart study). Am J Cardiol. 2015;115(7):890-4.

7. Mackey RH, Greenland P, Goff DJ, Lloyd-Jones D, Sibley CT, Mora S. High-density lipoprotein cholesterol and particle concentrations, carotid atherosclerosis, and coronary events: MESA (multi-ethnic study of atherosclerosis). J Am Coll Cardiol. 2012;60(6):508-16.

8. Kuller LH, Grandits G, Cohen JD, Neaton JD, Prineas R. Lipoprotein particles, insulin, adiponectin, C-reactive protein and risk of coronary heart disease among men with metabolic syndrome. Atherosclerosis. 2007;195(1):122-8.

9. Duprez DA, Kuller LH, Tracy R, Otvos J, Cooper DA, Hoy J, Neuhaus J, Paton NI, Friis-Moller N, Lampe F, et al. Lipoprotein particle subclasses, cardiovascular disease and HIV infection. Atherosclerosis. 2009;207(2):524-9.

10. Berger JS, McGinn AP, Howard BV, Kuller L, Manson JE, Otvos J, Curb JD, Eaton CB, Kaplan RC, Lynch JK, et al. Lipid and lipoprotein biomarkers and the risk of ischemic stroke in postmenopausal women. Stroke. 2012;43(4):958-66.

11. Otvos JD. Low-density lipoprotein and high-density lipoprotein particle subclasses predict coronary events and are favorably changed by gemfibrozil therapy in the veterans affairs high-density lipoprotein intervention trial. Circulation. 2006;113(12):1556-63.

12. Hsia J, Otvos JD, Rossouw JE, Wu L, Wassertheil-Smoller S, Hendrix SL, Robinson JG, Lund B, Kuller LH. Lipoprotein particle concentrations may explain the absence of coronary protection in the Women's Health Initiative hormone trials. Arterioscler Thromb Vasc Biol. 2008;28(9):1666-71.

13. Parish S, Offer A, Clarke R, Hopewell JC, Hill MR, Otvos JD, Armitage J, Collins R. Lipids and lipoproteins and risk of different vascular events in the MRC/BHF heart protection study. Circulation. 2012;125(20):2469-78.

14. El Harchaoui K, Arsenault BJ, Franssen R, Despre JP, Hovingh GK, Stroes ES, Otvos JD, Wareham NJ, Kastelein JJ, Khaw KT, et al. High-density lipoprotein particle size and concentration and coronary risk. Ann Intern Med. 2009:150(2):84-93.

15. Musunuru K, Orho-Melander M, Caulfield MP, Li S, Salameh WA, Reitz RE, Berglund G, Hedblad B, Engstrom G, Williams PT, et al. Ion mobility analysis of lipoprotein subfractions identifies three independent axes of cardiovascular risk. Arterioscler Thromb Vasc Biol. 2009;29(11):1975-80.

16. Kim DS, Li YK, Bell GA, Burt AA, Vaisar T, Hutchins PM, Furlong CE, Otvos JD, Polak JF, Arnan MK, et al. Concentration of smaller high-density lipoprotein particle (HDL-P) is inversely correlated with carotid intima media thickening after confounder adjustment: the multi ethnic study of atherosclerosis (MESA). J Am Heart Assoc. 2016;5(5) https://doi.org/10.1161/JAHA.115.002977.

17. Camont L, Chapman MJ, Kontush A. Biological activities of HDL subpopulations and their relevance to cardiovascular disease. Trends Mol Med. 2011;17(10):594-603.

18. Nofer JR, Brodde MF, Kehrel BE. High-density lipoproteins, platelets and the pathogenesis of atherosclerosis. Clin Exp Pharmacol Physiol. 2010;37(7):726-35.

\section{Ready to submit your research? Choose BMC and benefit from:}

- fast, convenient online submission

- thorough peer review by experienced researchers in your field

- rapid publication on acceptance

- support for research data, including large and complex data types

- gold Open Access which fosters wider collaboration and increased citations

- maximum visibility for your research: over $100 \mathrm{M}$ website views per year

At BMC, research is always in progress.

Learn more biomedcentral.com/submissions 